\title{
Vinte anos da Lei n.o 9.394/96, o que mudou? Politicas educacionais em busca de democracia
}

\author{
Gloria Maria Anselmo de Souza* \\ Gisele Coelho de Oliveira Araújo** \\ Waldeck Carneiro da Silva**
}

\begin{abstract}
RESUMO: O artigo reúne algumas reflexões sobre os vinte anos da LDBEN n. - 9394/96 em relação às mudanças ocorridas até hoje no aperfeiçoamento das orientações propostas. Pontua três alterações relacionadas ao processo de democratização da educação: alterações do artigo 26; ampliação do ensino fundamental para nove anos e a obrigatoriedade de escolarização formal a partir de quatro anos. Reflexões entendidas como iniciativas pautadas no fortalecimento da democracia, agora ameaçada por retrocessos e conservadorismos.
\end{abstract}

Palavras-chave: LDBEN. Políticas públicas. Democracia. Mudanças.

\section{Twenty years of Law No. 9394 / 96, what has changed? Educational policies in search of democracy}

\begin{abstract}
The article gathers some reflections on the twenty years of LDBEN no 9394/96 in relation to the changes that have occurred up to today in the improvement of the proposed guidelines. We note three amendments related to the process of democratization of education: amendments to article 26; extension of primary education to
\end{abstract}

* Doutora em Educação pela Universidade Federal Fluminense. Atualmente é pedagoga na rede municipal de educação de Niterói e professora de ensino médio da Secretaria de Estado de Educação do RJ. Niterói/ RJ-Brasil. E-mail: <gloriaanselmo50@gmail.com>.

** Mestranda em Educação pela Universidade Federal Fluminense. É Pedagoga da Fundação Municipal de Educação de Niterói. É integrante do NUGEPPE/UFF - Núcleo de Estudos e Pesquisas em Gestão e Políticas Públicas em Educação. Niterói/RJ - Brasil. E-mail: <coelho.gisa@hotmail.com>.

*** Doutor em Ciências da Educação pela Faculdade de Ciências Humanas e Sociais da Sorbonne (Universidade Paris V). Atualmente, é Professor Associado da Faculdade de Educação da UFF, com atuação no Programa de Pós-Graduação em Educação. Coordena o Grupo de Pesquisa em Políticas Públicas de Educação (GRUPPE/CNPq) e é deputado estadual no Rio de Janeiro (2015-2018). Niterói/RJ - Brasil. E-mail: <waldeckcarneiro@gmail.com>. 
nine years and the requirement of formal schooling after four years of age. Reflections, understood as initiatives aimed at strengthening democracy, now threatened by setbacks and conservatism.

Keywords: LDBEN. Public policy. Democracy. Changes.

\section{Veinte años de la Ley n⿳0 9.394/96, ¿qué ha cambiado?}

Políticas educativas en busca de la democracia

RESUMEN: Este artículo reúne algunas reflexiones sobre los veinte años de la LDBEN no 9394/96 por lo que respecta a los cambios ocurridos hasta el momento en el perfeccionamiento de las orientaciones propuestas. Señala 3 modificaciones relacionadas con el proceso de democratización de la educación: modificaciones del artículo 26; ampliación de la enseñanza fundamental para nueve años y la obligatoriedad de escolarización formal a partir de los cuatro años. Reflexiones entendidas como iniciativas basadas en el fortalecimiento de la democracia, ahora amenazada por retrocesos y conservadurismo.

Palabras clave: LDBEN. Políticas públicas. Democracia. Cambios.

\section{Vingt ans de la Loi n.o 9.394/96, qu'est-ce qui a changé?}

Politiques éducatives en quête de démocratie

RÉSUMÉ: Cet article réunit quelques réflexions sur les vingt ans de la LDBEN (loi de directives et de base de l'éducation nationale) $n .{ }^{-}$ 9394/96 et sur les changements effectivement réalisés aujourd'hui dans le perfectionnement des directions proposées. Il évalue trois changements relatifs au processus de démocratisation de l'éducation: les modifications de l'article 26, l'expansion de l'enseignement primaire pour 9 ans et l'obligation de la scolarisation formelle à partir des quatre ans de l'enfant. Ces réflexions se veulent des initatives de renforcement de la démocratie, aujourd'hui menacée par des reculs et les conservatismes.

Mots-clés: LDBEN. Politiques publiques. Démocratie. Changements. 


\section{Introdução}

$\mathrm{E}$

ste artigo busca empreender algumas reflexões sobre as mudanças incorporadas ao texto original da Lei de Diretrizes e Bases da Educação Nacional (LDBEN) no 9394/96, ao longo de seus 20 anos (1996-2016), com vistas ao aperfeiçoamento das orientações inicialmente propostas. Conscientes dos limites do texto, elegemos três alterações relacionadas ao processo de democratização da educação básica, a saber: algumas alterações incorporadas ao artigo 26; ampliação do ensino fundamental para nove anos; e a obrigatoriedade de escolarização formal desde os quatro anos de idade na educação infantil. Os três aspectos são de especial relevância no contexto de políticas públicas comprometidas com a transformação social, na qualificação da educação básica nos títulos I e II da própria lei, considerando-a como um direito. Como pontua Cury (2008):

A educação básica é um conceito mais do que inovador para um país que, por séculos negou, de modo elitista e seletivo aos seus cidadãos, o direito ao conhecimento pela ação sistemática da organização escolar. Resulta daí que a educação infantil é a raiz da educação básica, o ensino fundamental é o seu tronco e o ensino médio é seu acabamento. (CURY, 2008, p. 294-295)

Tomar como princípio, este conceito demandou inicialmente compreender o outro modo de perceber a educação como um direito civil/social inalienável que precisava explicitar-se frente às desigualdades, os conservadorismos que até então haviam permeado o contexto educacional brasileiro. Cury (2008) contribuiu para que este processo se desvelasse a partir das orientações previstas na Constituição Federal de 1988 e aprofundadas no Plano Nacional de Educação de 2001, historicizando o processo de elaboração do texto da LDBEN 9.394/96, que sinaliza para um conjunto de disputas e inúmeras lutas travadas para a garantia de tantos direitos privados à população brasileira. Mas, o texto original do texto legal deixou várias lacunas que necessitaram ser ajustados em forma de acréscimos, alterações e promulgação de leis complementares. Isto porque a realidade apontava demandas que não se cumpriam pela vontade de governantes. Por isso, a intervenção de setores da sociedade civil, de educadores e parlamentares comprometidos com a garantia de direitos impôs a expansão do texto legal, trazendo desafios que se materializaram em forma de alterações/incorporações.

Os movimentos sociais foram motores para as inúmeras alterações que criaram condições para que a lei federal se tornasse documento possível de se materializar no contexto educacional brasileiro, sempre marcado por uma diversidade expressiva, confrontada com a unicidade que os documentos oficiais guardam em si. Artigos suprimidos, outros modificados ou ampliados e ainda aqueles com redação nova, a fim de incluir elementos inéditos à época da promulgação da lei e que demandavam orientações mais detalhadas acerca de temas variados. Afinal, a realidade não é simples, nem linear. 
Assim, as demandas da sociedade brasileira impuseram um movimento de revisão do texto legal para evitar que se tornasse letra morta.

As estratégias metodológicas neste trabalho incluem análise documental de textos legais e de outros aportes teóricos.

\section{Mudanças na Lei nos últimos vinte anos}

Como sinaliza Cury (2008), a base e as ideias da LDBEN foram iniciadas antes da promulgação da Constituição Brasileira de 1988, no seio do processo efervescente dos movimentos sociais organizados que clamavam por outras propostas e concepções de educação capazes de criar elos com o movimento de redemocratização do País, ao longo dos anos de 1980. Educadores inconformados com as atrocidades educacionais produzidas pelo ideário do Regime Militar (1964 - 1985) iniciaram a organização de combate a um conjunto de ideias conservadoras e alienantes, que buscavam manter as camadas menos favorecidas em situação de submissão e dominação constantes. Os índices de analfabetismo, evasão e repetência eram alarmantes. Os currículos e modelos pedagógicos, precários, e o que havia de melhor destinava-se aos interesses das classes dominantes, representada por uma minoria da população. Enfim, os anos de chumbo deixaram uma marca triste e com resultados sofríveis que atravessaram as últimas três décadas e ainda assombram os dias atuais.

\section{Reorganização na estrutura curricular}

O artigo 26, que trata da questão curricular, foi alvo de várias modificações/inclusões das quais destacamos as seguintes:

Art. 26. Os currículos da educação infantil, do ensino fundamental e do ensino médio devem ter base nacional comum, a ser complementada, em cada sistema de ensino e em cada estabelecimento escolar, por uma parte diversificada, exigida pelas características regionais e locais da sociedade, da cultura, da economia e dos educandos. (Redação dada pela Lei nº 12.796, de 2013).

A primeira mudança significativa é a própria redação do caput do artigo 26. que em sua versão original, além de já propor uma base nacional comum, inclui a educação infantil como parte integrante da educação básica. Um ganho importante que coaduna com o reconhecimento desta etapa de ensino como integrante oficial da educação básica. É um dado relevante, considerando que ela esteve, historicamente, relegada à condição assistencialista, deixando a educação dos pequenos à dimensão do brincar e do cuidar. Mas e o educar? Não seria também importante à formação do ser humano? 
No texto alterado, brincar, cuidar e educar passaram a compor um processo que se inicia com a vida e prossegue até que ela se finde. Educar desde os primeiros meses do nascimento se configurava, assim, como um direito para todos os seres humanos, aspecto já comprovado pelas ciências e reflexões teóricas de autores que se dedicam a problematizar a infância.

Outro movimento de mudança foi demarcado em 2010 e, posteriormente, em 2013, com a obrigatoriedade do ensino de arte, defesa civil e educação ambiental como componentes curriculares obrigatórios.

$\S 20 \mathrm{O}$ ensino da arte, especialmente em suas expressões regionais, constituirá componente curricular obrigatório nos diversos níveis da educação básica, de forma a promover o desenvolvimento cultural dos alunos. (Redação dada pela Lei no 12.287 , de 2010).

$\S 7^{\circ}$ Os currículos do ensino fundamental e médio devem incluir os princípios da proteção e defesa civil e a educação ambiental de forma integrada aos conteúdos obrigatórios. (Incluído pela Lei nº 12.608, de 2012).

Estas mudanças sejam necessárias à operacionalização de avanços à humanização da vida em sociedade, apresentando-se como processos de fortalecimento do cenário educacional. Elas representam a materialização de um currículo dinâmico, vivo, comprometido com uma das transformações sociais, políticas e culturais pelas quais temos lutado tanto. No entanto, indagamos sobre a necessidade de legislar com tanto afinco sobre questões que deveriam fazer parte do pensamento coletivo de uma sociedade que se pretende democrática e emancipatória. O que move tais interesses?

Seguindo a linha das incorporações, o mesmo artigo ganha mais duas. Na primeira, o foco é o currículo de História do Brasil, incorporando contribuições das diferentes manifestações culturais, além das manifestações artísticas relacionadas às diferentes etnias que compõem originariamente a formação do povo brasileiro. A nova redação foi oriunda da Lei Federal 13.278/16, aprovada portanto, naquele ano.

$\S 4^{\circ} \mathrm{O}$ ensino da História do Brasil levará em conta as contribuições das diferentes culturas e etnias para a formação do povo brasileiro, especialmente das matrizes indígena, africana e europeia.

$\S 6^{\circ}$ As artes visuais, a dança, a música e o teatro são as linguagens que constituirão o componente curricular de que trata o $\S 2^{\circ}$ deste artigo. (Redação dada pela Lei $n^{\mathbf{0}}$ 13.278, de 2016).

Interessante observar a inclusão do parágrafo $9^{0}$ como orientação dada pela Lei Federal n. ${ }^{-13.010 / 14}$, tema curricular necessário, quando já existe legislação específica sobre os direitos das crianças e adolescentes, em vigor desde 1990, marcada inclusive pela judicialização para a infração desses direitos. Além disso, o texto parece ignorar o próprio teor da LDBEN, cuja marca principal é a garantia de direitos civis e sociais do ponto de vista educacional, o que parece gerar certa ambiguidade. 
$\S 90$ Conteúdos relativos aos direitos humanos e à prevenção de todas as formas de violência contra a criança e ao adolescente serão incluídos, como temas transversais, nos currículos escolares de que trata o caput deste artigo, tendo como diretriz a Lei no 8.069, de 13 de julho de 1990 (Estatuto da Criança e do Adolescente), observada a produção e distribuição de material didático adequado. (Incluído pela Lei $\mathrm{n}^{\mathrm{o}}$ 13.010, de 2014).

Este bloco de alterações se apresenta como conquistas significativas e valiosas quando se deseja mais justiça social e formação humana às demandas da atualidade. Lembrando os estudos de Edgar Morin (2002) sobre os saberes necessários à educação do futuro, chama a atenção a seguinte citação:

A educação para o futuro deverá ser o ensino primeiro e universal, centrado na condição humana. Estamos na era planetária; uma aventura comum conduz os seres humanos, onde quer que se encontrem. Estes devem reconhecer-se em sua humanidade comum e ao mesmo tempo reconhecer a diversidade cultural inerente a tudo o que é humano. (MORIN, 2002, p. 47)

As reflexões do teórico reafirmam os aspectos que foram introduzidos no texto legal ao longo dos anos. Afinal, quando se trata de educação e formação, nada está pronto, acabado. Ao contrário, as transformações sociais, políticas, econômicas e culturais não se esgotam em si mesmas. Elas nos desafiam e desafiam o mundo a reconduzir posturas, práticas, concepções e mentalidades. Educadores, legisladores e profissionais de educação estão confrontados permanentemente com esta compreensão. Cury (2008) também destaca que a educação básica como um direito "tomou a si a formalização legal do atendimento a determinados grupos sociais (...) como os afrodescendentes, que devem ser sujeitos de uma desconstrução de estereótipos, preconceitos e discriminação" (p. 300). Eis aí a origem do artigo 26-A, redigido em sua versão inicial por meio da Lei Federal 10.639/2003 e ampliado pela Lei 11.645/08.

Art. 26-A. Nos estabelecimentos de ensino fundamental e de ensino médio, públicos e privados, torna-se obrigatório o estudo da história e cultura afro-brasileira e indígena. (Redação dada pela Lei n⿳ำ 11.645, de 2008).

$\S 1^{\circ} \mathrm{O}$ conteúdo programático a que se refere este artigo incluirá diversos aspectos da história e da cultura que caracterizam a formação da população brasileira, a partir desses dois grupos étnicos, tais como o estudo da história da África e dos africanos, a luta dos negros e dos povos indígenas no Brasil, a cultura negra e indígena brasileira e o negro e o índio na formação da sociedade nacional, resgatando as suas contribuições nas áreas social, econômica e política, pertinentes à história do Brasil. (Redação dada pela Lei nº 11.645, de 2008).

$\S 2^{\circ}$ Os conteúdos referentes à história e cultura afro-brasileira e dos povos indígenas brasileiros serão ministrados no âmbito de todo o currículo escolar, em especial nas áreas de educação artística e de literatura e história brasileiras. (Redação dada pela Lei nº 11.645, de 2008). 
$\mathrm{O}$ artigo causou uma revolução nos contextos escolares e na sociedade civil, mas, como afirma a própria LDBEN em seu artigo 26, "§ $4^{\circ}$, “O ensino da História do Brasil levará em conta as contribuições das diferentes culturas e etnias para a formação do povo brasileiro, especialmente das matrizes indígena, africana e europeia. (BRASIL, 1996)". Esta alteração em particular tornou-se uma forte bandeira de luta dos movimentos sociais, organizados capitaneados pelo Movimento Negro, cuja iniciativa data de pelo menos dois séculos. Ela ganha uma força intensa e muitas conquistas vem se materializando por força da lei.

O texto da LDBEN se configurou como um rumo importante para a educação brasileira. Não obstante as contribuições para as limitações que apresentou, trouxe ricas orientações para o contexto educacional e vem sendo aperfeiçoado lentamente frente às transformações propostas pela dinamicidade da vida cotidiana expressa no seio das unidades escolares brasileiras.

\section{Alterações no ensino fundamental de nove anos}

A promulgação inicial da LDBEN estabeleceu a duração de escolaridade obrigatória no prazo máximo de oito anos. Ela ainda se pautava nas determinações da Lei 5.692/71, entretanto, a realidade educacional brasileira apontou para uma lacuna nos processos de aprendizagem dos primeiros anos de escolaridade. Além disso, pesquisas diversas sinalizavam para o fato de que a inclusão das crianças com seis anos de escolaridade no ensino fundamental favorecia de modo interessante a aprendizagem e o desenvolvimento psicossocial. Pautado nessa concepção, o Ministério da Educação abraçou a ideia de ampliação dessa etapa de ensino e, por meio da alteração proposta no artigo 32 da LBDEN, através da Lei n, $\stackrel{0}{11.274}$, de 05/02/2006, passou a vigorar a seguinte redação: "Art. 32. O ensino fundamental obrigatório, com duração de 9 (nove) anos, gratuito na escola pública, iniciando-se aos 6 (seis) anos de idade, terá por objetivo a formação básica do cidadão, mediante (...)".

A medida já havia sido apontada pela Lei n. ${ }^{\circ}$ 10.172/2001 (PNE) que instituiu o ensino fundamental de nove anos, posteriormente ratificado pela Resolução CNE/CEB n 3/2005, fixando como condição mínima para matrícula a obrigatoriedade de seis nos completos ou a completar no início do ano letivo. O mérito da medida também se sustentou na inclusão de um número maior de crianças mais precocemente no processo de escolarização, demandando inclusive uma reflexão mais profunda sobre os aspectos didáticos e pedagógicos necessários à mudança.

Ultrapassando os caminhos administrativos, o Ministério da Educação e a Secretaria de Educação Básica cuidaram de produzir os documentos norteadores para subsidiar a alteração do texto legal, dos quais destacamos: Ensino Fundamental de Nove Anos 
- Orientações para a Inclusão da Criança de Seis Anos de Idade (2007); Orientações Gerais - Ampliação do Ensino Fundamental para Nove Anos - Relatório do Programa (2004). Os documentos subsidiaram a análise e compreensão do processo, além de promover reflexões indispensáveis ao acolhimento das crianças de seis anos no ensino fundamental, à época, primeira etapa obrigatória da educação básica. Sobre a mudança, é possível considerá-la significativa, principalmente para as camadas populares da população brasileira. Ela representou um desafio importante para que estados e municípios buscassem ampliar suas redes de ensino e melhorar o atendimento. Como afirma Cury (2008, p. 302):

A função social da educação assume a igualdade como pressuposto fundamental do direito à educação, sobretudo nas sociedades politicamente democráticas e socialmente desejosas de maior igualdade entre as classes sociais e entre os indivíduos que as compõem e as expressam. Essas são as exigências que o direito à educação traz, a fim de democratizar a sociedade brasileira e republicanizar o Estado.

Este representa um dos caminhos para a transformação social e educacional urgente e necessária, mas ainda há muito o que realizar.

\section{A educação infantil na nova LDB}

Após a alteração na lei maior da educação brasileira (Lei de Diretrizes e Bases da Educação Nacional), o termo educação infantil e sua visão foram incluídos como primeira etapa da educação básica. É certo que a Constituição de 1988 já garantia o direito de crianças de zero a seis anos à educação em creches e pré-escolas, sendo reiterado no Estatuto da Criança e do Adolescente de 1990. No entanto, a inclusão deste direito em diretrizes e normas, na esfera da educação nacional, simboliza uma alteração histórica para a educação infantil no País.

\footnotetext{
No Brasil estamos vivendo um momento histórico muito oportuno para a reflexão e a ação em relação às políticas públicas voltadas para as crianças. Cada vez mais, a educação e o cuidado na primeira infância são tratados como assuntos prioritários por parte dos governos Federal, Estadual e Municipal, bem como pelas organizações da sociedade civil, por um número crescente de profissionais da área pedagógica e de outras áreas do conhecimento, que vêem na Educação Infantil uma verdadeira "ponte" para a formação integral do cidadão. (BARROS, 2008).
}

O artigo 22 da LDB, que trata da educação básica, expressa apenas duas finalidades: "fornecer ao aluno a formação comum indispensável para o exercício da cidadania; fornecer-lhe meios para progredir no trabalho e em estudos posteriores." Quando passa a ser uma etapa da educação básica, a educação infantil também contém, necessariamente, essas finalidades. 
A nova LDB garante à educação infantil uma relevância que não havia nas legislações precedentes. E é citada na Seção II, do capítulo II (da Educação Básica) nos termos a seguir:

Art. 29 A educação infantil, primeira etapa da educação básica, tem com finalidade o desenvolvimento integral da criança até os seis anos de idade, em seus aspectos físico, psicológico, intelectual e social, complementando a ação da família e da comunidade.

Art. 30 A educação infantil será oferecida em: I - creches ou entidades equivalentes, para crianças de até três anos de idade; II - pré-escolas para crianças de quatro a seis anos de idade.

Art. 31 Na educação infantil a avaliação far-se-á mediante acompanhamento e registro de seu desenvolvimento, sem o objetivo de promoção, mesmo para o acesso ao ensino fundamental

Vale ressaltar, além do que já foi analisado acerca da educação infantil como etapa da educação básica, a importância de a educação infantil favorecer o desenvolvimento da criança em todas as dimensões, de forma integral e integrada, representando a base para o completo e pleno desenvolvimento dos indivíduos. Para tanto, é fundamental a inseparável importância educacional e social do educar e cuidar.

A educação infantil precisa estar articulada às famílias e à comunidade. As ações precisam ser complementares, buscando o diálogo e a parceria entre elas. Há, no entanto, uma função característica das instituições de educação infantil no que diz respeito a acrescentar experiências, aumentar os conhecimentos do educando, o seu envolvimento com o ser humano, pela convivência e integração social.

Além disso, na observância das Diretrizes, a proposta pedagógica das instituições de educação infantil deve garantir que elas cumpram plenamente sua função sociopolítica e pedagógica:

Construindo novas formas de sociabilidade e de subjetividade comprometidas com a ludicidade, a democracia, a sustentabilidade do planeta e com o rompimento de relações de dominação etária, socioeconômica, étnico-racial, de gênero, regional, linguística e religiosa.

Ao evidenciar que a função da avaliação na educação infantil não está relacionada à promoção e não é condição para acesso ao ensino fundamental, a LDB se posiciona claramente contrária a retenção dos alunos na pré-escola até que estejam alfabetizados, o que impede ou atrasa o ingresso ao ensino fundamental. A avaliação implica referências, planejamento, critérios e objetivos, devendo ser formativa e orientadora, o que significa que deve ter o objetivo de aprimorar a prática educativa, acompanhar e registrar o desenvolvimento integral do aluno, como explicitado no artigo 29. 
Outros artigos da LDB deliberam sobre questões importantes à educação infantil. Por exemplo, quando a Lei trata "Da Organização da Educação Nacional” (capítulo IV), onde determina o regime de colaboração entre a União, os estados e os municípios no que diz respeito aos sistemas de ensino. É assegurada a responsabilidade fundamental do município na educação infantil, com o amparo financeiro e técnico dos governos federal e estadual.

Existe também o artigo das "Disposições Transitórias", que tem importância singular para a educação infantil. Trata-se do Art. 89, que assegura que "as creches e pré-escolas existentes ou que venham a ser criadas, no prazo de três anos, a contar da publicação desta lei, integrar-se-ão ao respectivo sistema de ensino".

Com o objetivo de cumprir este prazo, os sistemas de ensino e as instâncias que regulam a área da educação precisam estabelecer, com urgência, normas e diretrizes que assegurem a característica educativa das creches e pré-escolas e sua introdução nos sistemas e ensino.

Ainda são muitos os desafios que precisamos encarar e superar, e o atual momento histórico oportuniza reflexões sobre a educação infantil com foco nas crianças. A educação infantil cada vez mais é tratada como prioridade pelos governos e poderes legislativos.

\section{Alterações em relação à idade de escolarização}

A Lei de Diretrizes e Bases (LDB) nº 9.394 foi promulgada em 20 de dezembro de 1996. A partir desta data, ela vem incluindo os mais variados tipos de educação: educação infantil, que passou a ser obrigatória para crianças a partir de quatro anos; ensino fundamental; ensino médio, para os jovens até os 17 anos. Também inclui outras modalidades do ensino, como a educação especial, indígena, no campo e ensino a distância. Está sob nossa responsabilidade segui-la, contribuindo para que a educação brasileira seja mais humana e formativa, considerando que o sistema educacional envolve a família, as relações humanas, sociais e culturais.

Através da LDB, constatamos os princípios gerais da educação, assim como as finalidades, os recursos financeiros, a formação e diretrizes para a carreira dos profissionais da área educacional. A LDB se renova a cada período, sendo responsabilidade da Câmara dos Deputados sua atualização de acordo com o contexto da sociedade. Anteriormente, o prazo para concluir o ensino fundamental era de oito anos. Com a atualização da LDBEN, este prazo foi estendido para nove, tendo como idade inicial os seis anos. Houve outras atualizações, como a revogação dos parágrafos $2^{\circ}$ e $4^{\circ}$ do Artigo 36, da seção IV, que se refere ao ensino médio. Por isso, a relevância da sua divulgação, com o objetivo de direcionar os brasileiros, garantindo seus direitos e expondo seus deveres. 
Outra importante atualização da LDB no que diz respeito à educação infantil é o artigo 6oque estipula que "É dever dos pais ou responsáveis efetuar a matrícula das crianças na educação básica a partir dos 4 (quatro) anos de idade" (Redação dada pela Lei $n^{0}$ 12.796, de 2013). Ou seja, os pais não têm mais a opção e sim a obrigação de matricular seu filho de quatro anos na educação básica. A lei diz ainda que, a partir de 2016, os pais que não cumprirem o que determina os novos parâmetros da LDB poderão sofrer pena com multa ou detenção de quinze dias.

Ao longo de sua existência, algumas atualizações ocorreram na LDB. Uma muito expressiva está relacionada ao currículo da educação infantil, que deve seguir uma única base no Brasil, sem desconsiderar a diversidade cultural de cada região. $\mathrm{O}$ educador deverá acompanhar e avaliar o desenvolvimento dos educandos, porém sem a função de aprovar ou reprovar. Segundo a União Nacional dos Conselhos Municipais de Educação, estes procedimentos estabelecem a democratização do ensino no Brasil.

A nova determinação incorporada à Lei de Diretrizes e Bases de 1996, que estipula a obrigatoriedade do ensino dos 4 aos 17 anos, incluindo a pré-escola, o ensino fundamental e o médio é um grande avanço na direção da democratização do ensino e da educação para a democracia. Publicada no Diário Oficial da União, a lei altera a idade que os pais devem matricular seus filhos na escola, dos 6 anos para os 4 anos de idade. Fica estabelecido também que os estados e municípios têm até 2016 para oferecer vagas para crianças nesta faixa etária.

Nos embasamos em Benevides (1996), que afirma a importância de uma educação para a democracia, entendida a partir da universalização do acesso de todos à escola. Ao entendermos democracia, agregando questões políticas e sociais, a autora afirma a importância da soberania popular e do respeito integral aos direitos humanos, entre eles, a educação, que "é aqui entendida, basicamente, como a formação do ser humano para desenvolver suas potencialidades de conhecimento, julgamento e escolha para viver conscientemente em sociedade."

Antes da mudança na Constituição, o ensino fundamental era a única fase escolar obrigatória no Brasil. Depois da aprovação da emenda, o ensino passou a ser obrigatório dos 4 aos 17 anos, incluindo a pré-escola, o ensino fundamental e o médio.

Essa obrigatoriedade não descaracteriza as especificidades da educação infantil. Ela continua sendo uma etapa da educação básica e a criança continua sendo entendida como um sujeito histórico de direitos. De acordo com as Diretrizes,

Na transição para o Ensino Fundamental a proposta pedagógica deve prever formas para garantir a continuidade no processo de aprendizagem e desenvolvimento das crianças, respeitando as especificidades etárias, sem antecipação de conteúdos que serão trabalhados no Ensino Fundamental. (Diretrizes Curriculares Nacionais para a Educação Infantil, 2010, p. 30). 
Os demais itens da Lei 12.796, de 4 de abril de 2013, atualizam a Lei de Diretrizes e Bases e preveem que a educação infantil terá carga horária mínima anual de 800 horas e controle de frequência nas pré-escolas com frequência mínima de $60 \%$ do total de horas.

Incorporam a orientação de que o ensino seja ministrado, levando em consideração a diversidade étnico-racial e o atendimento educacional especializado gratuito aos alunos com deficiência, transtornos globais do desenvolvimento e altas habilidades ou superdotação.

A lei determina que a União, o Distrito Federal, os estados e municípios adotem mecanismos facilitadores de acesso e permanência em cursos de formação de docentes em nível superior para atuar na educação básica pública.

\section{LDBEN e qualidade da educação}

Existe uma pluralidade de significados atribuída aos significantes de qualidade da educação, do ensino, do currículo. O Plano Nacional de Educação aponta para a importância de uma escola com padrão de qualidade nacional. Para isso, são necessários recursos financeiros e pedagógicos, para que haja equalização de oportunidades de acesso e permanência na escola.

As alterações na LDB precisam surgir de demandas da população e precisam ser um processo democrático, envolvendo toda a comunidade escolar. A LDB deve garantir a autonomia do trabalho docente e a liberdade de organização curricular das escolas. A LDB não pode ser uma prisão de conteúdos, uma descrição engessada do que será ensinado em cada etapa, posto que não há como desconsiderar o acúmulo de reflexões e o protagonismo docente que se construíram ao longo da história sobre as questões curriculares, nos trazendo ao que temos hoje, e ainda precisa ser aperfeiçoado, mas de maneira reflexiva e crítica, levando-se em conta não apenas o que ensinar, mas quem e como aprende. Arroyo (2013) nos auxilia neste debate, ao apontar que

As relações entre os docentes e os ordenamentos curriculares passaram a ser um dos campos de estudo, de debates, de estudos, de encontros nas escolas e nos cursos de formação. De um lado os docentes da educação básica se tornaram mais autônomos como coletivos sociais, acumularam níveis de formação, conquistaram tempos de estudo, de planejamento, (...) mais autores e senhores de seu trabalho individual e sobretudo, coletivo. De outro lado, as diretrizes e normas, os ordenamentos e as lógicas curriculares continuam fiéis a sua tradicional rigidez, normatização, segmentação, sequenciação e avaliação. As recentes políticas de avaliação centralizada quantitativa se dão por desempenhos, por etapas, para quantificar progressos, sequências de ensino-aprendizagem, reforçarem lógicas progressivas, sequenciais rígidas, aprovadoras, reprovadoras de alunos e mestres. (ARROYO, 2013, p. 35). 


\section{Considerações finais}

A grande luta que vem sendo articulada nos diferentes contextos sociais se funda principalmente no protagonismo e relações emancipatórias (SANTOS, 2000), que se constroem nas práticas cotidianas, marca da grandiosidade do Brasil. Isto representa dizer que as lutas por mudanças na educação não podem se balizar pelo autoritarismo e conservadorismo, mas pela liberdade, pelo diálogo, pelo reconhecimento da diversidade cultural, econômica e social que nos envolve.

A LDBEN não será suficiente para, sozinha, promover o necessário salto de qualidade da educação pública brasileira. De toda forma, a Lei faz parte do extenso repertório de políticas necessárias para que esse salto seja possível - é necessário, entre outros pontos, financiamento adequado, condições de trabalho, formação continuada, valorização salarial e profissional dos trabalhadores da educação. Desse modo, as escolas serão capazes de assegurar inclusão e qualidade do ensino a todos os estudantes.

Este texto é um ponto de partida para outras reflexões e questionamentos. Não pretendemos aqui esgotar o debate, mas abrir caminho para novas problematizações e, mais ainda, um olhar cuidadoso frente ao cenário político que se articula neste momento, com imprecisões, incertezas e improvisações dos conservadorismos e autoritarismos, que tentam burlar a luta democrática em curso no País. Esta questão nos leva a indagar: o que e a quem queremos educar? Para que mundo, que sociedade?

Recebido em 16/10/2016 e aprovado em 10/01/2017

\section{Referências}

ARROYO, Miguel Gonzáles. Currículo, Território em Disputa. 5ạ ed. Petrópolis: Vozes, 2013.

BARROS, Miguel Daladier. Educação infantil: o que diz a legislação. Disponível em http://www.lfg. com.br. 12 de novembro de 2008.

BENEVIDES, Maria Victoria de Mesquita. Educação para a democracia. Lua Nova. Revista de Cultura e Política. São Paulo: CEDEC, n.38, p.223-235, 1996.

BRASIL. Constituição (1988). Constituição da República Federativa do Brasil. Congresso. Brasília, DF, 1988.

BRASIL. Lei 9.394, de 20 de dezembro de 1996. Estabelece as Diretrizes e Bases da Educação Nacional. Congresso. Brasília, DF, 1996.

BRASIL. Conselho Nacional de Educação. Resolução CNE/CEB № 5 de 17 de dezembro de 2009. 
BRASIL. Ministério da Educação. Secretaria de Educação Básica. Diretrizes Curriculares Nacionais para a Educação Infantil. Brasília: MEC/SEB, 2010.

BRASIL. Lei 13.005, de 25 de junho de 2014. Aprova o Plano Nacional de Educação - PNE. Congresso. Brasília, DF, 2014.

BRASIL. Ministério da Educação. Base Nacional Comum Curricular - Documento preliminar. MEC. Brasília, DF, 2015.

BRASIL. Ministério da Educação. Base Nacional Comum Curricular - Documento preliminar 2 versão revista. MEC. Brasília, DF, 2016.

CURY, Carlos Roberto Jamil. A Educação Básica como Direito. São Paulo:Cadernos de Pesquisa, v. 38, n. 134, p. 293-303, maio/ago. 2008.

FREIRE, Paulo. Pedagogia da Autonomia: Saberes necessários à prática educativa. Rio de Janeiro: Paz e Terra, 1996.

LÁZARO, André Luiz de Figueiredo in Revista Retratos da Escola. Brasília, v.7, n.13, 2013. Revistas Retratos da Escola. Brasília, DF, CNTE, nº 2/3 (2008), nº 13 (2013) e nº 16 (2015).

MACEDO, Elizabeth. Base Nacional Comum: Novas formas de sociabilidade produzindo sentidos para a educação. Revista e-Curriculum, São Paulo, v. 12, n. 3, p. 1530 - 1555, out./dez., 2014.

MORIN, Edgar. Os sete saberes necessários à educação do futuro. São Paulo: Cortez, 2002.

SANTOS, Boaventura de Souza. Crítica da Razão Indolente; contra o desperdício da experiência. São Paulo: Cortez, 2000.

VIEIRA, Juçara. Três reflexões sobre currículo. Cadernos de Educação. Brasília, DF, CNTE, n. 5, 1997. 